\title{
Commentary
}

\section{Adapting and retesting evidence-based child maltreatment prevention programs: a case study in Canada}

\author{
Christopher Mikton, PhD
}

Tweet this article

This special issue of Health Promotion and Chronic Disease Prevention in Canada is timely, as child maltreatment is a significant public health problem; globally, the number affected is at least in the hundreds of millions. One-quarter of adults report having been physically abused and over one-third emotionally abused as children; one in 5 women and one in 13 men report having been sexually abused. ${ }^{1-3}$ Recent national surveys of violence against children conducted in Africa and in other low- and middle-income countries reveal rates of childhood physical, sexual and emotional abuse even higher than the global rates. ${ }^{4}$

"Imagine," Dr James Mercy, Director of the Violence Prevention Division at the US Centers for Disease Control and Prevention $^{5}$ (US-CDC) suggests, "that you woke up this morning and newspaper headlines said that scientists had discovered a new disease. The scientists reported that up to 1 billion children worldwide were exposed to this disease every year. And that over the course of their lifetimes children exposed to this disease were at greater risk for mental illnesses like depression and anxiety disorders; at greater risk for chronic diseases such as diabetes, heart disease, and cancer; at greater risk of infectious diseases like HIV; and, if that wasn't enough, at greater risk for involvement in social problems like crime and drug abuse. If we had such a disease, what do you think we'd do? The truth is we do have such a "disease"; it's violence against children.”

Several organizations, including US-CDC, the World Health Organization, the United Nations Children's Fund and the Public Health Agency of Canada, to name but a few, have identified child maltreatment prevention as a global health priority and have supported efforts to take sustained and effective action to prevent it.

But there is a major obstacle. Currently, strategies to prevent child maltreatment that are both demonstrably effective and scalable to the national population are rare.

The Nurse-Family Partnership (NFP) is one of the few.

The NFP was developed in the United States, and the three randomized controlled trials that demonstrated its effectiveness at preventing child maltreatment (by almost onehalf) and many other negative outcomes have all been conducted in the US. As this special issue rightly emphasizes, and as the literature of cross-cultural adaptation of evidence-based interventions makes clear, ${ }^{6-8}$ we cannot assume that the NFP will produce the same impressive results when implemented elsewhere, and it is necessary for it to undergo a careful process of adaptation, retesting and refining to ensure it remains effective. Canada is making a concertedand exemplary-effort to this effect.

Jack et al. ${ }^{9}$ describe the rigorous process of initial adaptation, feasibility assessment and acceptability the NFP is undergoing in Ontario and British Columbia. Perceptions of the health care and social service professionals involved in referrals to the NFP and who provide services to NFP families is the focus of the paper by $\mathrm{Li}$ et $\mathrm{al}^{10}$ These researchers address the critical challenge of integrating NFP into an existing network of services. Hovdestad et al. ${ }^{11}$ examine whether it is the youngest mothers-whom the NFP usually targets-whose children are at highest risk of negative outcomes.

Jack et al. ${ }^{9}$ describe a process of adaptation and re-evaluation that goes beyond the fourstep model required by Dr. David Olds, the program developer, and his staff at the Prevention Research Center at the University of Colorado Denver ${ }^{12}$ They included an additional process evaluation and a study examining potential biological mechanisms linking the intervention and the behavioural outcomes in children. This augmented process will thus include six phases: (1) adaptation; (2) assessment of feasibility and acceptability; (3) a randomized controlled trial to evaluate effectiveness; (4) a process evaluation; (5) a study of potential biological mechanisms; and (6) replication and expansion. The rigour of the process and the fact that it is being so carefully documented, through these papers among other means, will contribute to developing an empirically validated method for the cross-country and cross-cultural adaptation of child maltreatment prevention programs. ${ }^{13-15}$

Jack et al. ${ }^{9}$ raise some difficult questions concerning the process of cross-cultural and

Author reference:

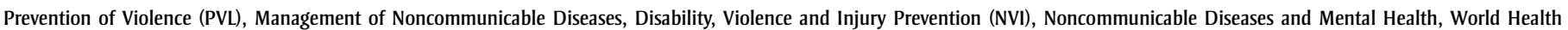
Organization, 20 Avenue Appia, CH-1211 Geneva 27, Switzerland

Correspondence: Christopher Mikton, World Health Organization, 20 Avenue Appia, CH-1211 Geneva 27, Switzerland; Email: miktonc@who.int 
cross-context adaptation and evaluation. These questions are likely to become starker as the NFP and similar interventions are implemented in lower-resource countries that are culturally distant from the countries that developed the interventions. There is a consensus among the different models and frameworks for cross-cultural and crosscontext adaptation that it is critical to maintain fidelity to the essential-or causally effective-components of the intervention so that it preserves its effectiveness in the new setting. ${ }^{7,16-19}$ To do so, however, requires these components be empirically identified through methods such as decomposing trials, mediational analyses and micro-trials. ${ }^{20}$ The extent to which the 18 model elements specified by the NFP are causally effective and how faithfully they each have to be implemented before the intervention begins to lose its effectiveness remain unclear. $^{21}$

The study by Li et al. ${ }^{10}$ points to one such possible essential ingredient, the one-to-one and long-term "therapeutic" relationship between the public health nurse and the client. This study highlights the credibility of the evidence-base supporting the NFP in the eyes of health care and social service professionals and the perception that, even in a high-resource setting such as Canada, NFP is filling a major gap. Li et al. ${ }^{10}$ also ask to what extent the effectivenessparticularly the long-term effectiveness-of the NFP depends on the quality of, and degree of integration with, services provided in parallel to and after the mothers have completed the NFP. In lower-resource settings with fewer nurses, the feasibility of sustaining an expensive stand-alone intervention such as NFP might be a challenge, making the identification of key ingredients and the integration, in the long term, of these ingredients into standard service delivery all the more important.

Using a sample of mothers from the Canadian Incidence Study of Reported Child Abuse and Neglect, Hovdestad et al. ${ }^{11}$ found that mothers under 22 years of age are generally at higher risk for poor child health and developmental outcomes than those who are older. In particular, they identify higher rates of modifiable risk factors, such as receiving social assistance, alcohol abuse, or lack of social support, in this population.
This provides empirical confirmation that early childhood interventions, such as the NFP, should be targeting this population as a matter of priority. However, it will be important to consider whether younger mothers remain at higher risk in countries and cultures where giving birth at a young age is more normative. Such countries include Bangladesh, Ethiopia, Mexico and Nicaragua, where $40 \%, 22 \%, 39 \%, 28 \%$, respectively, of women have given birth by the age of 18 years. $^{22}$

This careful process of adaptation and retesting of the NFP underway in Canada holds great promise for the field of child maltreatment prevention globally. It is hoped that this process will contribute to developing empirically based methods for cross-country and cross-cultural adaptation and validation, which are currently sorely lacking and, without which, it is unlikely that evidence-based interventions can ever sufficiently expand globally to prevent this "disease"-one that affects hundreds of millions of children around the world.

\section{References}

1. Stoltenborgh M, Bakermans-Kranenburg MJ, Alinik LR, Van IM. The university of childhood emotional abuse: a meta-analysis of worldwide prevalence. J Aggress Maltreat Trauma. 2012;21(8):870-90. DOI: 10.1080/ 10926771.2012.708014.

2. Stoltenborgh M, Bakermans-Kranenburg MJ, Ijzendoorn MJ, Alink LRA. Cultural-geographical differences in the occurrence of child physical abuse? A meta-analysis of global prevalence. Int J Psychol. 2013;48(2):81-94. DOI: $10.1080 / 00207594.2012 .697165$.

3. Stoltenborgh M, Van IM, Euser EM, Bakermans-Kranenburg MJ. A global perspective on child sexual abuse: meta-analysis of prevalence around the world. Child Maltreat. 2011;16(2):79-101. DOI: 10.1177/ 1077559511403920 .

4. Injury Prevention \& Control: Division of Violence Prevention. Towards a violence-free generation: using science to fuel action and end violence against children [Internet]. Atlanta (GA): US Centers for Disease Control and Prevention; 2015 [cited 2015 May 1]. Available from: http://www.cdc.gov/violence prevention/vacs/index.html
5. Mercy J. CDC measures violence against children, sparks action [Internet]. Atlanta (GA): CDC Foundation; 2013 Nov 25 [cited 2015 May 1]. Available from: http://www. cdcfoundation.org/blog-entry/cdc-measuresviolence-against-children-sparks-action

6. Barrera M Jr, Castro FG, Steiker LK. Critical analysis of approaches to the development of preventive interventions for subcultural groups. Am J Community Psychol. 2011;48 (3-4):439-54. DOI: 10.1007/s10464-010-9422-X.

7. Cuijpers P, de Graaf I, Bohlmeijer E. Adapting and disseminating effective public health interventions in another country: towards a systematic approach. Eur J Public Health. 2005;15 (2):166-9. DOI: 10.1093/eurpub/cki124.

8. United Nations Office on Drugs and Crime. Guide to implementing family skills training programmes for drug abuse prevention [Internet]. New York: United Nations; 2009 Feb [cited 2015 May 1]. Available from: http://www.unodc.org/documents/preven tion/family-guidelines-E.pdf

9. Jack SM, Catherine N, Gonzalez A, MacMillan HL, Sheehan HD, Waddell C, For the British Columbia Healthy Connections Project Scientific Team. Adapting, piloting and evaluating complex public health interventions: lessons learned from the Nurse-Family Partnership in Canadian public health settings. Health Promo Chronic Dis Prev Can. 2015;35(8/9):151-9.

10. Li SA, Jack SM, Gonzalez A, Duku E, MacMillan H. Health care and social service professionals' perceptions of a home-visit program for young, first-time mothers. Health Promot Chronic Dis Prev Can. 2015;35(8/9):160-7.

11. Hovdestad W, Shields M, Williams G, Tonmyr L. Vulnerability within families headed by teen and young adult mothers investigated by child welfare services in Canada. Health Promot Chronic Dis Prev Can. 2015;35(8/9):143-50.

12. Prevention Research Center for Family and Child Health. Nurse-Family Partnership international program [Internet]. Denver (CO): University of Colorado Denver; [cited 2014 Dec 4].

13. Castro FG, Barrera M Jr, Steiker LKH. Issues and challenges in the design of culturally adapted evidence-based interventions. Annu Rev Clin Psychol. 2010;6:213-39. DOI:10.1146/ annurev-clinpsy-033109-132032. 
14. Lau AS. Making the case for selective and directed cultural adaptations of evidence-based treatments: Examples from parent training. Clin Psychol-Sci Pr. 2006;13(4):295-310. DOI: 10.1111/j.1468-2850.2006.00042.x.

15. Mikton C. Two challenges to importing evidence-based child maltreatment prevention programs developed in high-income countries to low-and middle income countries: generalizability and affordability. In: H. Dubowitz, editor. World Perspectives on Child Abuse. 10th edition. Aurora (CO): International Society for the Prevention of Child Abuse and Neglect; 2012.

16. Falicov CJ. Commentary: On the wisdom and challenges of culturally attuned treatments for Latinos. Fam Process. 2009;48(2):292-309. DOI: $10.1111 / j .1545-5300.2009 .01282 . x$.

17. Leerlooijer J, Ruiter RA, Reinders J, Darwisyah W, Kok G, Bartholomew L. The World Starts With Me: using intervention mapping for the systematic adaptation and transfer of schoolbased sexuality education from Uganda to Indonesia. Transl Behav Med. 2011;1(2): 331-40. DOI:10.1007/s13142-011-0041-3.

18. Wingwood GM, Diclemente RJ. The ADAPT-ITT model: a novel method of adapting evidence-based HIV Interventions. J Acquir Immune Defic Syndr. 2008;47: S40-6. DOI:10.1097/QAI.0b013e3181605.

19. Kumpfer KL, Pinyuchon M, Teixeiria DMA, Whiteside HO. Cultural adaptation process for international dissemination of the Strengthening Families Program. Eval Health Prof. 2008;31(2):226-39. DOI: 10.1177/ 0163278708315926 .

20. Leijten P, Dishion TJ, Thomaes S, Raajimakers MA, de Castro BO, Matthys W. Bringing parenting interventions back to the future: how randomized microtrials may benefit parenting intervention efficacy. Clin Psychol. 2015;22(1):47-57. DOI: 10.1111/ cpsp.12087.

21. Nurse-Family Partnership. Nurse-Family Partnership model elements [Internet]. Denver (CO): Nurse-Family Partnership; 2011 [cited 2015 May 1]. Available from: http://www.nursefamilypartnership.org/ communities/model-elements

22. Statistics and monitoring. Country statistics [Internet]. New York: UNICEF; 2015 [cited 2015 May1]; Available from: http://www. unicef.org/statistics/index_countrystats.html 